\title{
Performance of palm oil as a biobased machining lubricant when drilling inconel 718
}

\author{
Erween Abd Rahim ${ }^{1}$, Hiroyuki Sasahara ${ }^{2}$ \\ ${ }^{1}$ Precision Machining Research Center (PREMACH), Faculty of Mechanical and Manufacturing Engineering, UniversitiTun Hussein \\ Onn Malaysia, 86400 Parit Raja, Johor, Malaysia \\ ${ }^{2}$ Department of Mechanical System Engineering, Tokyo University of Agriculture and Technology, 2-24-16 Naka-cho, Koganei-shi, \\ 184-8588 Tokyo, Japan
}

\begin{abstract}
Metalworking fluid acts as cooling and lubrication agent at the cutting zone in the machining process. However, conventional Metalworking fluid such mineral oil gives negative impact on the human and environment. Therefore, the manufacture tends to substitute the mineral oil to bio-based oil such as vegetables and synthetic oil. In this paper, the drilling experiment was carried out to evaluate the efficiency of palm oil and compare it with minimal quantity lubrication technique using synthetic ester, flood coolant and air blow with respect to cutting temperature, cutting force, torque and tool life. The experimental results showed that the application of palm oil under minimal quantity lubrication condition as the cutting fluid was more efficient process as it improves the machining performances.
\end{abstract}

\section{Introduction}

Drilling process can be divided into either short hole drilling or deep hole drilling. A short hole is defined as a hole with a small ratio of depth to a diameter. Typically, it includes holes up to $30 \mathrm{~mm}$ having a depth of not more than five times the diameter. Meanwhile, for holes greater than $30 \mathrm{~mm}$ in diameter, the depth is usually more than 2.5 times hole diameter. Drilling performance can be measured in terms of thrust force, torque, power, tool life, dimensional accuracy and surface quality. Each of these measures is affected by various factors such as the tool and workpiece materials properties, the tool geometry, the cutting conditions, cutting fluid and machine tool. Drilling can be considerably the most difficult while milling and turning were the easiest in the machining process. Many researchers have studied the machinability of aeroengine alloys in the past, especially in the turning and milling process. Although extensive investigation reports have been published, considerable progress is being made and reported on the drilling of these alloys.

Ezugwu et al. [1] stated that approximately $50 \%$ of the total consumption in the manufacture of an aircraft engine is nickel-based alloys. These refractory materials may come in wrought (bar, sheet, large forging) and casting. Nickel-based alloys can be divided into three sub-categories namely nickel-copper, nickel-chromium-iron and nickel-molybdenumchromium. Many of the industrial nickel-based alloys contain alloying elements, including chromium, aluminium, titanium, molybdenum, tungsten, niobium, tantalum and cobalt. It has an excellent track record for providing corrosion resistance, high strength at high temperatures and aesthetic beauty in a wide range of applications. In most mentioned cases, Inconel 718 meets the requirements for many of the components in the aerospace engine. A major used of nickel-based alloys is in the manufacture of aerospace turbine blades whom the operating temperature is exceeded $500^{\circ} \mathrm{C}$. An analysis on the chemical content of nickel-based alloys revealed that machining problems could be occurred due to the relatively high percentage of nickel, cobalt and chromium content.

Basically, work hardening, low thermal conductivity, abrasiveness, high strength level and high heat generated were the dominant reasons for the difficulty in machining aeroengine alloys. Excessive heat could damage the cutting tool. Furthermore, lack of rigidity when holding the tool holder with cutting tool and workpiece can also shorten the tool life. Prolong machining also caused severe chipping and fracture of the tool edge. Cracks on the cutting tool and fracture of the entire cutting edge were mainly observed when machining aeroengine alloys.

Chen and Liao [2] summarized that wear can be divided into four stages; coated layer is abraded-off, then followed by flank wear and chipping at the outer cutting edge, formation of chipping and lastly the wear rate increases drastically and the cutting action is now replaced by extrusion. Azarhoushang and Akbari [3] developed a ultrasonic-assisted drilling method (UAD) in order to improve the hole quality. They found that 
the conventional drilling method suffered from catastrophic failure where the drills broke at the cutter exit. In addition, the UAD shows significant improvement in drill's lives. The study on the effect of minimal quantity lubrication (MQL) and biobased lubricant was conducted Rahim and Sasahara [4-8]. They found that the biobased lubricant made from palm oil significantly improved the drilling performance in terms of tool life and surface integrity under the MQL condition.

Unlike flood machining, previous researches showed that the machining of nickel based alloys is still limited especially when the effectiveness of the MQL approach has taken into consideration. In addition, much of the previous work done on MQL machining has been focused on the application of turning and milling process, however little research has been completed on drilling. In addition, published literature contains few articles on the performance of vegetable oil, in fact it can be an alternative to aforementioned cutting fluid. The main objective of this research is to highlight and investigate the drilling performance under various coolant-lubricant conditions, as well as a different type of MQL fluids namely synthetic ester and palm oil.

\section{Experimental details}

\subsection{Drilling tests under external coolant supply}

Drilling tests were performed using a Mazak Nexus 410-A machining center. These tests were conducted on the Inconel 718 with a diameter and thickness of 50 $\mathrm{mm}$ and $20 \mathrm{~mm}$, respectively, which was mounted on a piezoelectric dynamometer (Kistler 9365) as shown in Fig. 1. The dynamometer was connected to the charge amplifier and data logger system to measure and congregate the thrust force and torque data. All drills were AlTiN coated indexable carbide (Mitsubishi TAWNH1400T) with a diameter of $14 \mathrm{~mm}$. The point and helix angles were $130^{\circ}$ and $30^{\circ}$, respectively. The tool shank was collet mounted with an $80 \mathrm{~mm}$ overhang. A type-K thermocouple wires were embedded in the workpiece and located $9 \mathrm{~mm}$ (TC1) and $17 \mathrm{~mm}$ (TC2) from the top of the workpiece surface. The distance between the thermocouple wire to the hole wall is approximately $1.25 \mathrm{~mm}$.

In this experiment, the cutting speed of $30 \mathrm{~m} / \mathrm{min}$ and feed rate of $0.05 \mathrm{~mm} / \mathrm{rev}$ were employed. The through hole was drilled under the action of the external air blow, minimum quantity of lubricant (MQL) and flood coolant conditions (water soluble type). Synthetic ester (MQLSE) and palm oil (MQLPO) were used as the lubricant for the MQL condition. The physical characteristics of the MQL lubricants are summarized in Table 1.

\subsection{Drilling tests under internal coolant supply}

A series of MQL drilling tests under internal throughcoolant supply were performed on the same machining center as described earlier. Fig. 2 shows the experimental setup with a rotating $20 \mathrm{~mm}$ diameter of Inconel 718 bar and a stationary $14 \mathrm{~mm}$ diameter of AlTiN coated indexable carbide drill (Mitsubishi TAWNH1400T). The overhang of the workpiece and the drill were kept constant at $5 \mathrm{~mm}$ and $75 \mathrm{~mm}$, respectively. The thrust force during the drilling tests was measured with a Kistler 9257B dynamometer. The force signals were acquired by a data acquisition system connected to the personal computer. The type$\mathrm{K}$ thermocouple wires were embedded in the cutting tool and located near to the cutting edge, denoted as TC1 and TC2. The cutting speeds were 30, 40 and 50 $\mathrm{m} / \mathrm{min}$ at two feed rates of 0.05 and $0.1 \mathrm{~mm} / \mathrm{rev}$. A commercial available MQL unit was used to deliver the mist spray via an internal through-coolant. The lubricants used in this experiment are synthetic ester (MQLSE) and palm oil (MQLPO).

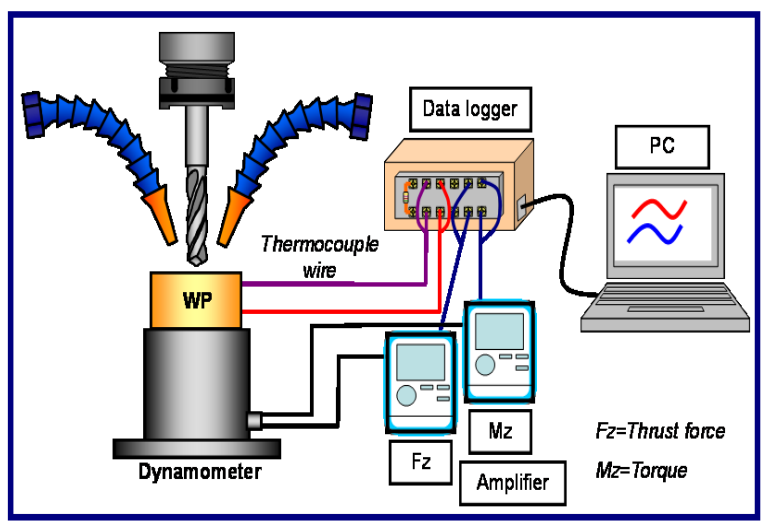

Fig. 1. Set up for external coolant supply

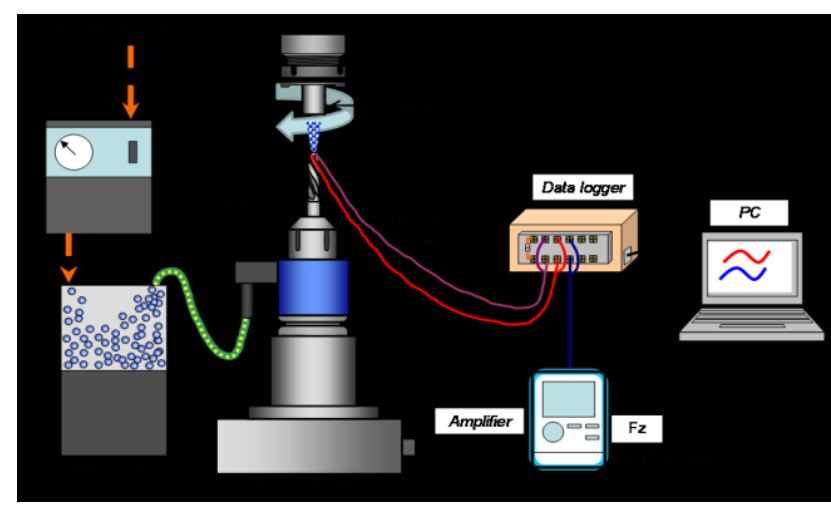

Fig. 2. Set up for internal coolant supply

\section{Result And discussion}

\subsection{Performance of various coolant conditions under external supply}

Fig. 3 shows the results of thrust force and torque at a constant cutting speed and feed rate of $30 \mathrm{~m} / \mathrm{min}$ and $0.05 \mathrm{~mm} / \mathrm{rev}$. It can be seen that MQLPO yielded 
significantly lower thrust force than the MQLSE, flood and air blow conditions. The MQLPO condition yielded a mean thrust force of $2638 \mathrm{~N}$, while the MQLSE condition yielded a mean thrust force of 2886 $\mathrm{N}$. Furthermore, the air blow condition recorded the highest thrust force value $(3699 \mathrm{~N})$ followed by the flood condition $(3443 \mathrm{~N})$. These results indicated that the thrust force was reduced by $40 \%$ (MQLPO), 28\% (MQLSE) and $7 \%$ (flood) relative to the air blow condition. The values of torque obtained while drilling Inconel 718 depicted that the MQLPO gave the lowest torque, whereas MQLSE and flood yielded slightly lower torque values than the air blow condition. The results indicate improved performance of the MQLPO condition up to $24 \%$, followed by MQLSE (23\%) and flood $(7 \%)$ relative to the air blow condition.

The results show that thrust force and torque are considerably less with the application of coolant (flood, MQLSE and MQLPO) compared to the air blow condition. This performance is due to the ability of coolant-lubricant to both reduce the cutting temperature and the friction thus preventing seizure at the tool-chip interface. However, the flood condition exhibits slightly higher thrust force and torque values than the MQL condition. The application of the MQL condition (MQLSE and MQLPO) substantially affected the thrust force and torque results. Furthermore, the MQLPO condition recorded the lowest thrust force and torque values. This suggests that MQLPO was a more effective lubricant than MQLSE. A vegetable oil such as palm oil consists of a high percentage of unsaturated fatty acid in the carbon chain. Unsaturated fatty acids contain double bonds which are easily broken with high temperature [9]. This enhances the formation of high lubrication strength film on the tool-chip or tool-workpiece interface.
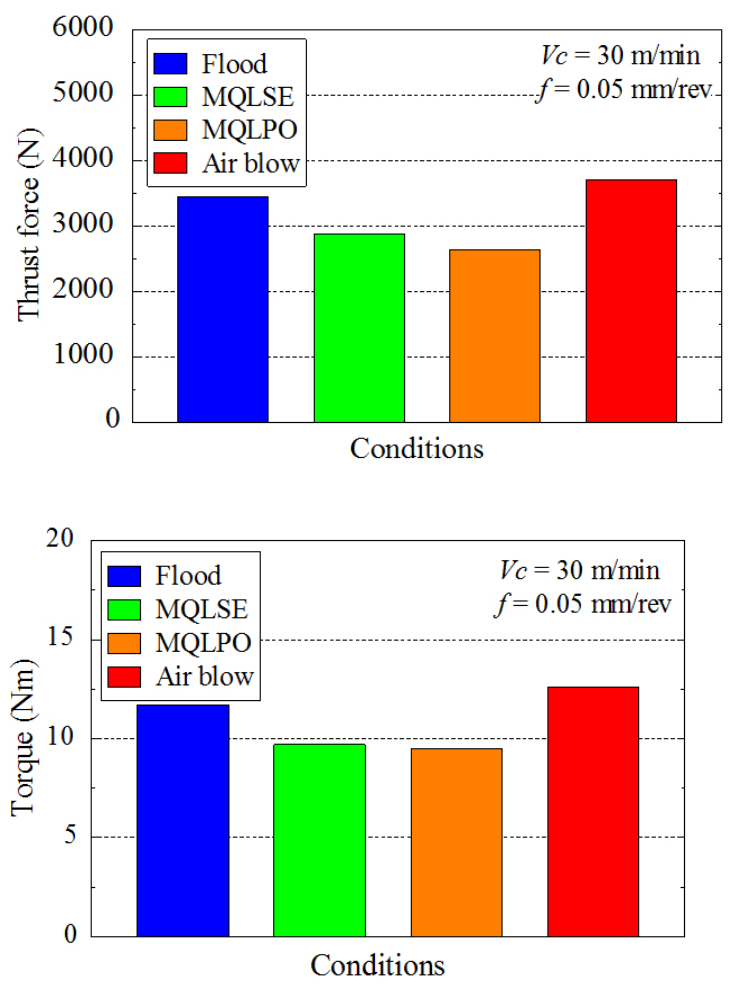

Fig. 3. Results of thrust force and torque
Fig. 4 shows the maximum workpiece temperature obtained under different coolant-lubricant conditions when drilling Inconel 718 at the cutting speed and feed rate of $30 \mathrm{~m} / \mathrm{min}$ and $0.05 \mathrm{~mm} / \mathrm{rev}$, respectively. In this experiment, the air blow condition yielded the highest workpiece temperature at $\mathrm{TC} 1$

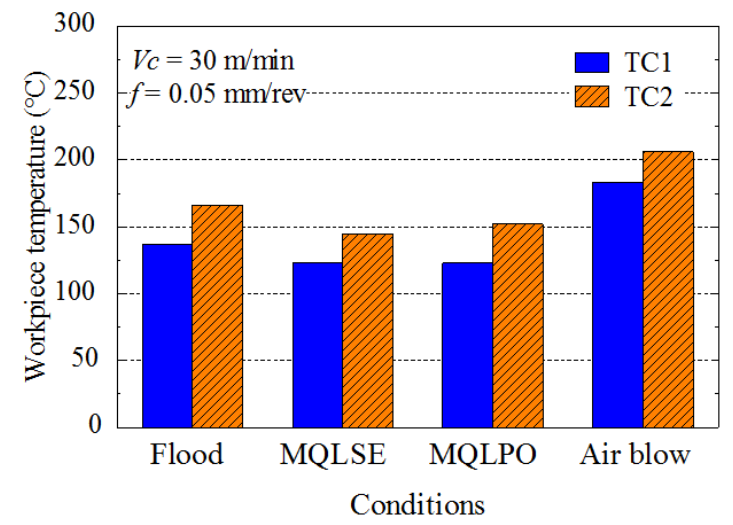

Fig. 4. Results of temperature
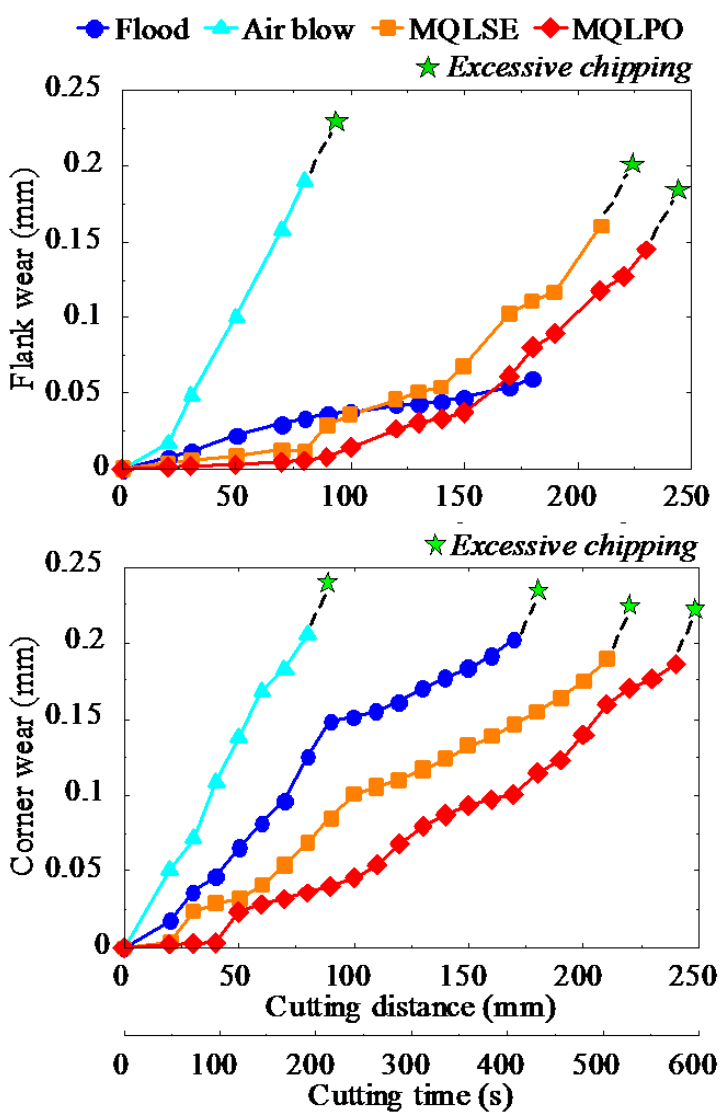

Fig.5. Tool wear progression

and $\mathrm{TC} 2$ with the value of $183^{\circ} \mathrm{C}$ and $209^{\circ} \mathrm{C}$, respectively. This was due to the poor cooling effect performed by the air blow. Also, it was observed that both MQL conditions yielded slightly lower temperatures than the air blow and flood conditions. At $\mathrm{TC} 1$ and $\mathrm{TC} 2$, the workpiece temperature of the flood condition indicated a reduction of $25 \%$ and $19 \%$, respectively, as opposed to the air blow condition. 
Furthermore, the MQLSE condition exhibited a reduction of $33 \%$ and $30 \%$ at $\mathrm{TC} 1$ and $\mathrm{TC} 2$ at both locations. MQLPO, however, showed a comparable performance with MQLSE with a reduction of 33\% and $26 \%$.

Fig. 5 illustrates the variation of flank wear and corner wear at the cutting speed of $30 \mathrm{~m} / \mathrm{min}$ and feed rate of $0.05 \mathrm{~mm} / \mathrm{rev}$ under various coolant-lubricant conditions. Drilling of Inconel 718 under the air blow conditions revealed a rapid flank and corner wear progression. The cutting tool under this condition suffered from excessive chipping after 90 seconds. Additionally, a large amount of workpiece material was observed adhering to the cutting tool. The flank wear progression curves under the flood, MQLSE and MQLPO conditions were almost the same. However, at the corner region, the wear rate for the flood condition accelerates faster than the MQLPO followed by the MQLSE condition. A tool life of 414, 507 and 578 seconds was recorded under the flood, MQLSE and MQLPO conditions, respectively.

It was found that the application of MQL (MQLSE and MQLPO) can efficiently cool and lubricate the tool-chip interface, thus improving the tool life. The considerable improvement in the MQL condition is due to the high velocity of small droplets of lubricant that penetrate into the tool-chip interface more effectively than in the flood condition. Accordingly, the cutting temperature and cutting force are expected to be reduced and, consequently, the tool life improved.

\subsection{Performance Of Various Coolant Conditions Under Internal Supply}

Fig. 6 shows the variation of thrust force for MQLSE and MQLPO conditions via internal through-tool supply when drilling Inconel 718. In general, thrust force decreased with an increase in cutting speed and decrease in the feed rate. Furthermore, thrust force under MQLPO condition is lower than under MQLSE condition at all tested cutting speeds and feed rates. This figure shows that drilling at the feed rate of 0.05 $\mathrm{mm} / \mathrm{rev}$ decreased the thrust force of MQLSE and MQLPO conditions by $25 \%$ and $24 \%$ respectively, when the cutting speed increases from 30 to $50 \mathrm{~m} / \mathrm{min}$. Meanwhile, MQLSE and MQLPO conditions recorded the thrust force reduction by $6 \%$ and $12 \%$ respectively, at the feed rate of $0.1 \mathrm{~mm} / \mathrm{rev}$. Furthermore, drilling at the lower feed rate of $0.05 \mathrm{~mm} / \mathrm{rev}$ reduced the thrust force of MQLSE condition by $17 \%$ for the cutting speed of $30 \mathrm{~m} / \mathrm{min}, 24 \%$ for the cutting speed of 40 $\mathrm{m} / \mathrm{min}$ and $38 \%$ for the cutting speed of $50 \mathrm{~m} / \mathrm{min}$. In addition, MQLPO condition recorded the reduction of $18 \%$ for the cutting speed of $30 \mathrm{~m} / \mathrm{min}, 22 \%$ for the cutting speed of $40 \mathrm{~m} / \mathrm{min}$ and $32 \%$ for the cutting speed of $50 \mathrm{~m} / \mathrm{min}$.

The observation revealed that high thrust force at lower cutting speeds is believed to be due to the presence of a built-up edge on the cutting edges, thus increasing the tool-chip friction as well as thrust force. Moreover, thrust forces were lowest at the higher cutting speed. This reduction is due to the decreased of tool-chip contact length and corresponding decrease in the friction of tool-chip interface. The phenomenon of lower thrust force by increasing the cutting speed can also be elucidated by the temperature influence. Higher temperature generates at high cutting speed thus the lower resistance against chip formation causes a lower thrust force and results in the thinner chip. It can be seen that the thrust forces also increased in feed rate. This is because the higher feed rate leads to a increase in the volume of material removed and more deformation energy is required for chip formation. It is evident from Fig. 6 that the thrust forces are lower under MQLPO condition as compared with MQLSE condition. This is due to the reduction of the friction at the tool-chip interface under MQLPO condition.

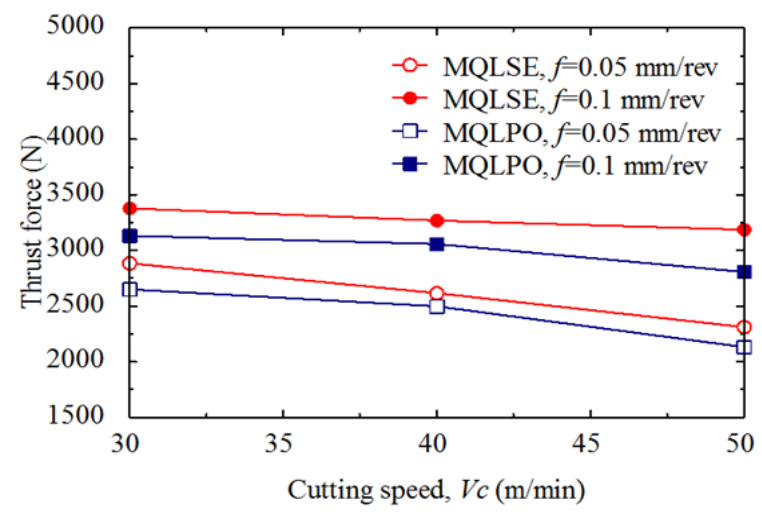

Fig. 6. Thrust force for MQLSE and MQLPO
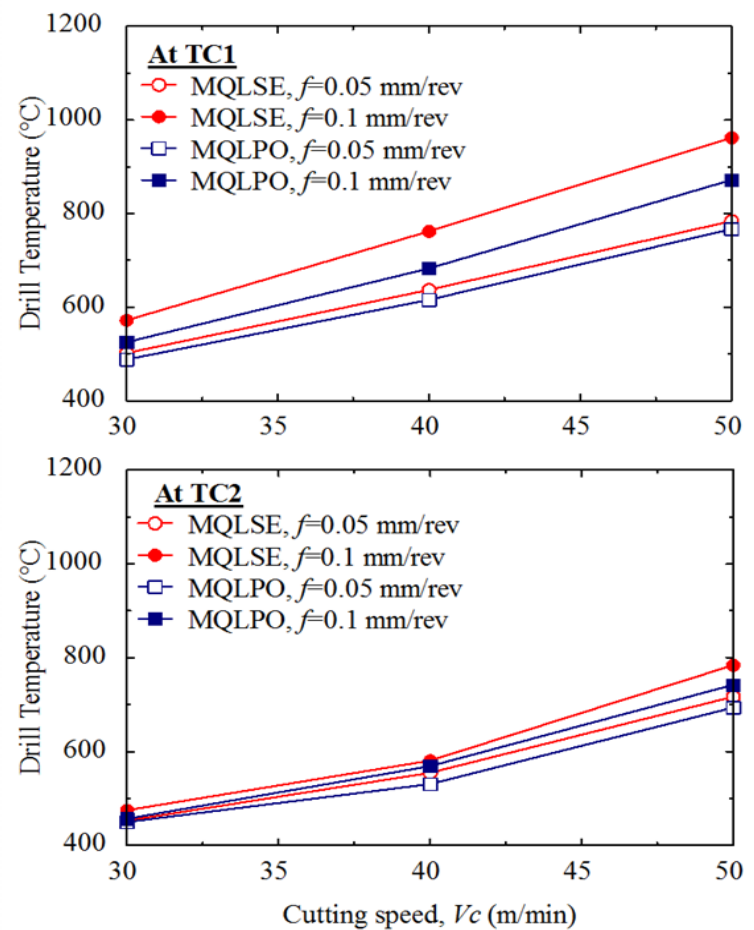

Fig. 7. Maximum drill temperature at $\mathrm{TC} 1$ and $\mathrm{TC} 2$ for MQLSE and MQLPO 
Fig. 7 illustrates the maximum temperature on the cutting edges measured at TC1 and TC2, respectively. An examination of these figures revealed that the drill temperature is affected by the main effects of the cutting speed, feed rate and lubricants. Increasing the cutting speed and feed rate significantly increases the drill temperature. For instance, under the MQLSE condition, the tool temperature at $\mathrm{TC} 1$ and $\mathrm{TC} 2$ goes up from $502^{\circ} \mathrm{C}$ to $784^{\circ} \mathrm{C}$ and $453{ }^{\circ} \mathrm{C}$ to $717^{\circ} \mathrm{C}$ at the feed rate of $0.05 \mathrm{~mm} / \mathrm{rev}$ when the cutting speed change from 30 to $50 \mathrm{~m} / \mathrm{min}$, while the tool temperature goes up from $572{ }^{\circ} \mathrm{C}$ to $962{ }^{\circ} \mathrm{C}$ and from $475{ }^{\circ} \mathrm{C}$ to $784{ }^{\circ} \mathrm{C}$ at the feed rate of $0.1 \mathrm{~mm} / \mathrm{rev}$. Furthermore, MQLPO condition indicates an increment of tool temperature at TC1 and TC2 from $488^{\circ} \mathrm{C}$ to 767 ${ }^{\circ} \mathrm{C}$ and from $450{ }^{\circ} \mathrm{C}$ to $694{ }^{\circ} \mathrm{C}$ at the feed rate of 0.05 $\mathrm{mm} / \mathrm{rev}$. In addition, the drill temperature also rises from $525^{\circ} \mathrm{C}$ to $872{ }^{\circ} \mathrm{C}$ and $457^{\circ} \mathrm{C}$ to $742{ }^{\circ} \mathrm{C}$ at the feed rate of $0.1 \mathrm{~mm} / \mathrm{rev}$.

Fig. 7 also revealed that the drill temperature generated for feed rate of $0.05 \mathrm{~mm} / \mathrm{rev}$ was lesser than the drill temperature generated for the feed rate of 0.1 $\mathrm{mm} / \mathrm{rev}$. For instance, for the thermocouple positioned at $\mathrm{TC} 1$, the recorded drill temperature values at the cutting speed of $50 \mathrm{~m} / \mathrm{min}$ for MQLSE condition were $784{ }^{\circ} \mathrm{C}$ (feed rate of $0.05 \mathrm{~mm} / \mathrm{rev}$ ) and $962^{\circ} \mathrm{C}$ (feed rate of $0.1 \mathrm{~mm} / \mathrm{rev})$. Under the same cutting speed, MQLPO condition recorded $767{ }^{\circ} \mathrm{C}$ (feed rate of 0.05 $\mathrm{mm} / \mathrm{rev}$ ) and $872{ }^{\circ} \mathrm{C}$ (feed rate of $0.1 \mathrm{~mm} / \mathrm{rev}$ ). The result indicates the reduction of $23 \%$ and $14 \%$ for MQLSE and MQLPO conditions, respectively. It is believed that the reduction of drill temperature was due to the reduction of contact time at the tool-chip interface during the machining process, subsequently reduces the friction. High feed rate also generates higher stress at the cutting tool edge thus promotes localized heat built-up in the cutting tool. The drill temperature is reduced in the presence of MQLPO condition compared to that when drilling with MQLSE condition. As stated in previous section, the viscosity of palm oil (MQLPO) was higher than that of synthetic ester (MQLSE). This suggests that the friction was reduced as the viscosity was increased, thus improved the lubrication condition.

\section{Conclusions}

Based on the analysis results, the evaluation of MQLPO and MQLSE was determined. The following conclusions can be drawn from this study;
MQLPO outperformed MQLSE and other coolant techniques in terms of cutting force, torque, cutting temperature and tool life. It can be suggested that the vegetable oil such as palm oil consists of a high percentage of unsaturated fatty acid in the carbon chain. This enhances the formation of high lubrication strength film on the tool-chip or tool-workpiece interface.

\section{Acknowledgments}

The authors thank the Ministry of Education Malaysia and UniversitiTun Hussein Onn Malaysia for the financial support via Fundamental Research Grant Scheme (Vot 1467).

\section{References}

1. E. O. Ezugwu, Z. M. Wang, A. R. Machado. Journal of Material Processing Technology, 86 (1999), 1-16.

2. Y. C. Chen, Y. S. Liao, Y. Study on wear mechanisms in drilling of Inconel 718 superalloy, Journal of Materials Processing Technology, 140 (2003), 269-273.

3. B. Azarhoushang, J. Akbari. 47 (2007), $1027-$ 1033.

4. E. A. Rahim, H. Sasahara. An Analysis of Surface Integrity when Drilling Inconel 718 using Palm Oil and Synthetic Ester under MQL Condition. Machining Science and Technology, 15 (1) (2011) 76-90.

5. E. A. Rahim, H. Sasahara. Surface Integrity in MQL Drilling Nickel-Based Superalloy. Key Engineering Materials, 447-448 (2010) 811-815.

6. E. A. Rahim, H. Sasahara. Surface Integrity in MQL Drilling Nickel-Based Superalloy. Key Engineering Materials, 447-448 (2010) 811-815.

7. E. A. Rahim, H. Sasahara. Surface Integrity when Drilling Nickel-Based Superalloy under MQL Supply. Key Engineering Materials, 443 (2010), 365-370.

8. E. A. Rahim, H. Sasahara. Application of Minimum Quantity Lubrication when Drilling Nickel-Based Superalloy at High Cutting Speed. Key Engineering Materials, 407-408 (2009)612615.

9. N. Talib, E. A. Rahim. Procedia CIRP, (2015) 346-350. 